\title{
Kinetics and Reaction Pathways for Propane Dehydrogenation and Aromatization on Co/H-ZSM5 and H-ZSM5
}

\author{
Sara Y. Yu, Grace J. Yu, Wei Li, and Enrique Iglesia* \\ Department of Chemical Engineering, University of California at Berkeley, Berkeley, California 94720
}

Received: August 22, 2001; In Final Form: January 31, 2002

\begin{abstract}
$\mathrm{Co} / \mathrm{H}-\mathrm{ZSM} 5$ catalyzes propane dehydrogenation and aromatization reactions. Initial product selectivities, product site-yields, and the ${ }^{13} \mathrm{C}$ content and distribution in the products of $2-{ }^{13} \mathrm{C}$-propane show that propane undergoes two primary reactions-dehydrogenation to propene and $\mathrm{H}_{2}$ and cracking to methane and ethene. Propene and ethene then form aromatics via oligomerization-cracking reactions and both ethene and propene hydrogenate to form ethane and propane, respectively, via both hydrogen transfer from coadsorbed intermediates and dissociative adsorption of $\mathrm{H}_{2}$. These reaction pathways resemble those occurring on H-ZSM5, but Co cations provide an alternate pathway for the removal of hydrogen atoms in adsorbed intermediates as $\mathrm{H}_{2}$. A kinetic model was used to describe experimental rates based on these observations and to obtain rate constants for individual reaction steps as a function of Co content and $\mathrm{H}_{2}$ concentration. $\mathrm{H}_{2}$ inhibits propane dehydrogenation to propene and alkene conversion to aromatics, and increases the rate and the rate constant for ethene hydrogenation. Rate constants were obtained for propane reactions on H-ZSM5 and Co/H-ZSM5 $(\mathrm{Co} / \mathrm{Al}=0.05-0.22)$. Propane dehydrogenation $\left(k_{1}\right)$, ethene hydrogenation $\left(k_{3}\right)$, and alkene dehydrocyclization $\left(k_{4}\right)$ rate constants increased with increasing $\mathrm{Co} / \mathrm{Al}$ ratio, because Co cations catalyze both the recombinative desorption of $\mathrm{H}_{2}$ and its microscopic reverse, the dissociative adsorption of $\mathrm{H}_{2}$. Co cations increase the reversibility of hydrogen adsorption-desorption steps, and in this manner, they increase the deuterium content in all products of $\mathrm{C}_{3} \mathrm{H}_{8}-\mathrm{D}_{2}$ reactions. Propane cracking rate constants $\left(k_{2}\right)$ were not influenced by Co cations, because cracking occurs on acid sites and its stoichiometry and mechanism do not require hydrogen.
\end{abstract}

\section{Introduction}

Co-exchanged H-ZSM5 catalysts have been recently reported to catalyze alkane dehydrocyclodimerization reactions. ${ }^{1}$ As in the case of $\mathrm{Zn}$ - and Ga-exchanged zeolites, these reactions appear to proceed via bifunctional pathways involving acidic $\mathrm{OH}$ groups and exchanged cations. ${ }^{2-9} \mathrm{Co} / \mathrm{H}-\mathrm{ZSM} 5$ shows higher propane turnover rates (per $\mathrm{Al}$ ) and aromatic and $\mathrm{H}_{2}$ site-time yields than $\mathrm{H}-\mathrm{ZSM}^{1}$ because $\mathrm{Co}^{2+}$ cations catalyze the recombinative desorption of $\mathrm{H}$-atoms as $\mathrm{H}_{2}$, as shown previously also for $\mathrm{Zn}^{2+}$ cations in H-ZSM5., ${ }^{2,9}$ This desorption step is not quasiequilibrated during alkane reactions on any of these materials and catalytic sites provided by these cations remove the kinetic bottlenecks that limit the rate and selectivity of alkane dehydrocyclodimerization reactions. Co/H-ZSM5 exhibits lower propane conversion rates and aromatics formation rates than $\mathrm{Zn} / \mathrm{H}-\mathrm{ZSM}$, because $\mathrm{Zn}^{2+}$ cations catalyze recombinative desorption steps more effectively than $\mathrm{Co}^{2+}$ cations. ${ }^{1,10}$

In this study, we describe detailed reaction pathways involved in propane dehydrogenation and aromatization on Co/H-ZSM5 by measuring product selectivities, site-yields as a function of contact time, and the ${ }^{13} \mathrm{C}$ isotopomer distributions in products of $2-{ }^{13} \mathrm{C}-\mathrm{C}_{3} \mathrm{H}_{8}$ reactions. The resulting kinetic model was used to probe the influence of $\mathrm{H}_{2}$ and the role of Co cations for each reaction step. The reversibility of $\mathrm{H}_{2}$ desorption steps was probed by measuring the isotopic content in the products formed from $\mathrm{C}_{3} \mathrm{H}_{8} / \mathrm{D}_{2}$ reactants.

* Author to whom correspondence should be addressed at 201 Gilman Hall, Berkeley, CA 94720. Phone: 510-642-9673. Fax: 510-642-4778. E-mail: iglesia@cchem.berkeley.edu.

\section{Experimental Methods}

Catalyst Synthesis. Co/H-ZSM5 catalysts with $\mathrm{Co} / \mathrm{Al}$ ratios of $0.05-0.31$ were prepared by contacting H-ZSM5 (prepared from Na-ZSM5; Zeochem, Si/Al $=14.5$, <5\% extraframework $\mathrm{Al}$ ) with aqueous 0.05 or $0.5 \mathrm{M} \mathrm{Co}\left(\mathrm{NO}_{3}\right)_{2}$ solutions ( $\mathrm{Co}-$ $\left(\mathrm{NO}_{3}\right)_{2} \cdot 6 \mathrm{H}_{2} \mathrm{O}$, Aldrich, $\left.99 \%\right)$ at $353 \mathrm{~K}$ for varying periods of time. Samples were then filtered, washed with $2 \mathrm{~L}$ of deionized water, dried in ambient air overnight at $393 \mathrm{~K}$, and treated in flowing dry air (Airgas, zero grade) at $773 \mathrm{~K}$ for $20 \mathrm{~h}$. The Co content was measured by atomic absorption (Galbraith Laboratories, Inc.). Previous $\mathrm{D}_{2}-\mathrm{OH}$ exchange and infrared studies quantified the remaining number of $\mathrm{OH}$ groups after cation exchange. ${ }^{1}$ Temperature programmed reduction studies showed that Co cations in $\mathrm{Co} / \mathrm{H}-\mathrm{ZSM} 5$ do not reduce in $\mathrm{H}_{2}$ up to 1273 $\mathrm{K}$ and Co K-edge X-ray absorption spectra showed that Co cations remain as divalent cations during reactions of $\mathrm{C}_{3} \mathrm{H}_{8}$ at $773 \mathrm{~K} .{ }^{1}$ Additional synthesis and characterization details of the H-ZSM5 and Co/H-ZSM5 samples have been reported elsewhere. ${ }^{1,8,11,12}$

Catalytic Studies. All catalytic rate measurements were performed using a recirculating batch reactor at $773 \mathrm{~K} .{ }^{1,9}$ The reactor contents were circulated at $>2 \mathrm{~cm}^{3} \mathrm{~s}^{-1}$ in order to ensure differential conditions and low propane conversions per pass $(<1 \%)$. Catalyst samples were pretreated in flowing air (Airgas, zero grade) at $773 \mathrm{~K}$ for $1 \mathrm{~h}$ before catalytic experiments.

Catalytic measurements were carried out using the following reactant mixtures:

(i) premixed $\mathrm{C}_{3} \mathrm{H}_{8} / \mathrm{He}$ (Praxair, certified mixture, 20.0\% $\mathrm{C}_{3} \mathrm{H}_{8}$ ); (ii) $\mathrm{C}_{3} \mathrm{H}_{8}$ (Matheson, $99.99 \%$ purity) mixed within the batch reactor with varying amounts of $\mathrm{He}$ (Airgas, UHP) or $\mathrm{H}_{2}$ 
SCHEME 1: Reaction Pathways for Propane Conversion on M/H-ZSM5 (Adapted from ref 16)

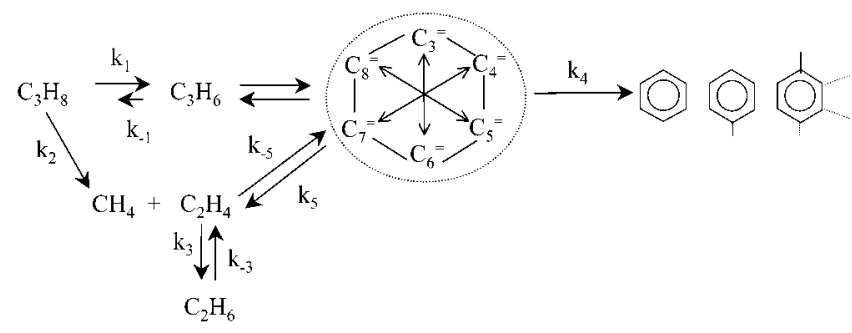

(Airgas, UHP); (iii) $2-{ }^{13} \mathrm{C}-\mathrm{C}_{3} \mathrm{H}_{8}$ (Isotec, 99\% purity) diluted with $\mathrm{He}$ (Airgas, UHP); and (iv) premixed $\mathrm{C}_{3} \mathrm{H}_{8} / \mathrm{D}_{2} / \mathrm{He}$ (Praxair, certified mixture, $20.0 \% \mathrm{C}_{3} \mathrm{H}_{8}, 10.3 \% \mathrm{D}_{2}$ ).

The concentrations of reactants and products were measured using capillary gas chromatography (Hewlett-Packard 5890; HP-1 methyl-silicone column, $50 \mathrm{~m}, 0.32-\mathrm{mm}$ diameter, 1.05 $\mu \mathrm{m}$ film thickness) and flame ionization detection. The deuterium and ${ }^{13} \mathrm{C}$ contents in reactants and products were measured using electron-impact mass spectrometry (Hewlett-Packard 5972, mass selective detector). Mass spectra were corrected for ion fragmentation and natural ${ }^{13} \mathrm{C}$ abundance in order to obtain isotopomer distributions. ${ }^{13}$ The amount of propane converted is reported as turnovers (propane molecules converted per remaining $\mathrm{OH}$ group) and product formation is reported as siteyields (propane molecules appearing as a given product per remaining $\mathrm{OH}$ group) as a function of contact time. Propane turnover rates or product site-time yields can be obtained from these data by dividing by the contact time (in batch reactors) or the residence time (in flow reactors) required to achieve a given number of turnovers or site-yields. Product selectivities are reported on a carbon basis as the percentage of the converted propane appearing as a given product. $\mathrm{H}_{2}$ selectivities are obtained from a hydrogen mole balance, as the percentage of the $\mathrm{H}$ atoms in the converted propane that do not appear in the hydrocarbon reaction products.

Kinetic Model. A kinetic model was used to describe the effects of contact time and of $\mathrm{H}_{2}$ concentration on the rate of formation of individual products on H-ZSM5 and Co/H-ZSM5 with varying $\mathrm{Co} / \mathrm{Al}$ ratio. The reaction scheme used is shown in Scheme 1. A well-mixed batch reactor mass balance was used with the following rate constants: $k_{1}, k_{-1}, k_{2}, k_{3}, k_{-3}, k_{4}$, $k_{5}$, and $k_{-5}$. First-order concentration dependences on the corresponding alkane reactants or reactive alkene intermediates were assumed for all reactions. Reverse rate constants for steps 1 and $3\left(k_{-1}\right.$ and $\left.k_{-3}\right)$ were related to the corresponding forward rate constant $\left(k_{1}\right.$ and $\left.k_{3}\right)$ by the equilibrium constants for the corresponding stoichiometric reaction.

A well-known library for solving ordinary differential equations ${ }^{14}$ was used to solve this system of ordinary differential equations. The regression analysis was done using an efficient code, ${ }^{15}$ which estimated parameters (rate constants, $k$ 's) by minimizing the function,

$$
\sum_{i=1}^{M} \sum_{j=1}^{N}\left(\frac{\hat{\mathrm{y}}_{i j}\left(k^{{ }^{s}}\right)-y_{i j}}{y_{i j}}\right)^{2}
$$

In eq $1, \hat{y}_{i j}$ are the model prediction for the calculated concentrations of reactant or products for a given set of rate constants, $y_{i j}$ are the corresponding experimental concentrations, $i$ is a given data point, and $j$ is a given component. All the rate constants were assumed to be positive.

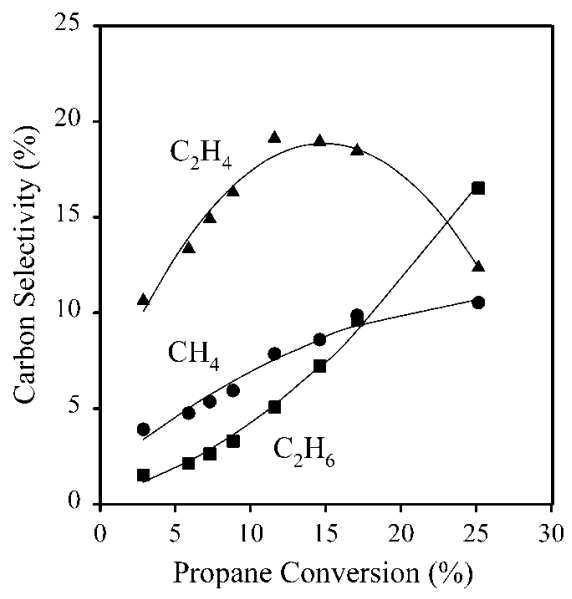

Figure 1. $\mathrm{C}_{1}-\mathrm{C}_{2}$ product selectivities with varying propane conversion on Co/H-ZSM5 [Co/Al $=0.17,773 \mathrm{~K}, 21.5 \mathrm{kPa} \mathrm{C}_{3} \mathrm{H}_{8}$, balance He].

\section{Results and Discussion}

Reaction Pathways of Propane Dehydrocyclodimerization on Co/H-ZSM5. On Co/H-ZSM5, propane reaction pathways include primary dehydrogenation steps that form $\mathrm{C}_{3} \mathrm{H}_{6}$ and primary cracking steps that form $\mathrm{CH}_{4}$ and $\mathrm{C}_{2} \mathrm{H}_{4}$ directly from propane. ${ }^{1}$ Secondary products include $\mathrm{C}_{2} \mathrm{H}_{6}$ and $\mathrm{C}_{6}-\mathrm{C}_{8}$ aromatics. ${ }^{1}$ Aromatics form via dehydrocyclization reactions of $\mathrm{C}_{6+}$ alkenes, which form and participate in rapid acid-catalyzed oligomerization-cracking cycles, as previously reported on $\mathrm{Zn} /$ H-ZSM5 and Ga/H-ZSM5., ${ }^{2,7-9}$

Initial propene selectivities (extrapolated to zero reactant conversion) show a nonzero value, because propene forms directly from propane, but aromatic selectivities are initially very low and increase with increasing conversion, as expected from their formation via secondary reactions of alkenes. ${ }^{1}$ Methane, ethene, and ethane selectivities are shown as a function of conversion on $\mathrm{Co} / \mathrm{H}-\mathrm{ZSM} 5(\mathrm{Co} / \mathrm{Al}=0.17)$ in Figure 1. Initial methane and ethene carbon selectivities are approximately $4 \%$ and $8 \%$, respectively, as expected from their equimolar formation in propane cracking reactions. Initial ethane selectivities are very low and they increase with increasing contact time. Methane and ethene selectivities also increase initially with contact time but ethene selectivities reach a maximum of $\sim 19 \%$ at $15 \%$ conversion and then decrease. Similar trends are observed on samples with other $\mathrm{Co} / \mathrm{Al}$ ratios and also on H-ZSM5.

These conclusions are consistent with the product site-yields plots shown in Figures 2 and 3 on Co/H-ZSM5 $(\mathrm{Co} / \mathrm{Al}=0.12)$. Methane site-yields increase linearly with contact time, suggesting that methane forms predominantly from propane and not from the propene products, which become more abundant with increasing contact time (Figure 2). Ethene site-yield curves show that ethene formation rates, given by the local slope of the site-yield curve, decrease, while ethane formation rates increase, with increasing contact time (Figure 3). If the ethene formed via propane cracking reactions did not react further, the rate of ethene formation would remain constant and ethene siteyields would remain twice the value measured for methane. The ethene site-yield curve expected from equimolar formation of methane and ethene is given by the solid line in Figure 3. At contact times longer than $4 \mathrm{ks}$, ethene site-yields become lower than expected, because of its secondary conversion to ethane and aromatics (Figure 3). The sum of the ethene and ethane site-yields or total $\mathrm{C}_{2}$ site-yields remains similar to the expected ethene site-yield (solid line), indicating that ethene is converted 


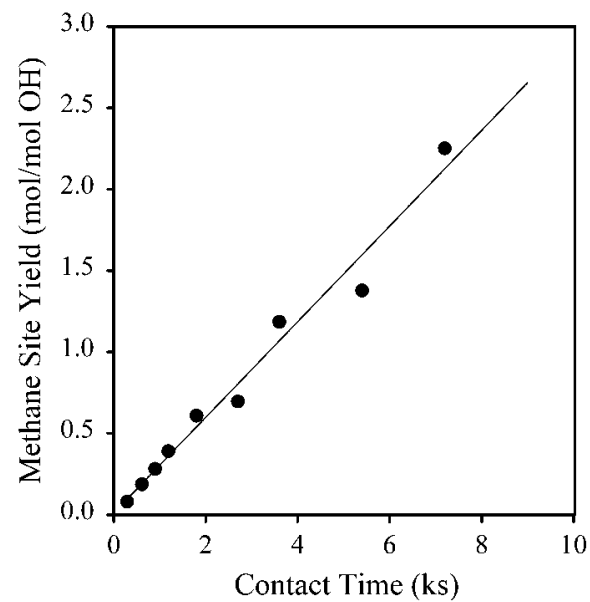

Figure 2. Methane site-yield with time on stream $[\mathrm{Co} / \mathrm{Al}=0.12,773$ $\mathrm{K}, 21.5 \mathrm{kPa} \mathrm{C}_{3} \mathrm{H}_{8}$, balance $\left.\mathrm{He}\right]$.

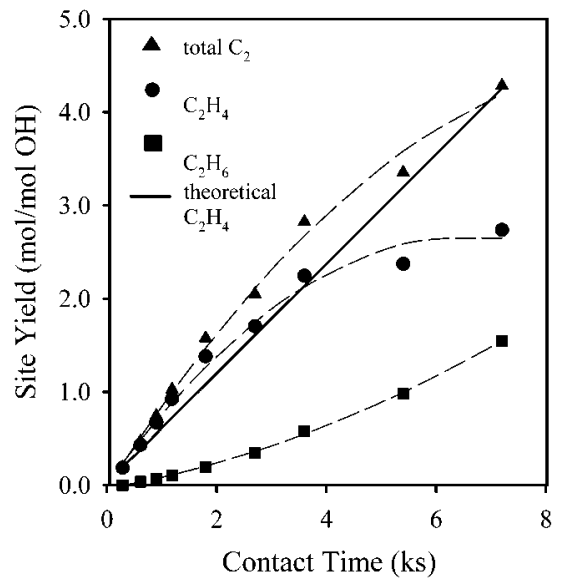

Figure 3. Ethene and ethane site-yields with time on stream $[\mathrm{Co} / \mathrm{Al}$ $=0.12,773 \mathrm{~K}, 21.5 \mathrm{kPa} \mathrm{C}_{3} \mathrm{H}_{8}$, balance $\left.\mathrm{He}\right]$.

predominantly to ethane. Therefore, it appears that ethene is mainly consumed via hydrogenation reactions to form ethane, although some ethene undergoes oligomerization with other alkenes and ultimately leads to higher alkenes and aromatics.

The ${ }^{13} \mathrm{C}$ content and the isotopomer distribution in products formed from $2-{ }^{13} \mathrm{C}$-propane reactants can also be used to probe propane reaction pathways. Oligomerization-cracking cycles lead to increasingly binomial isotopomer distributions as alkenes spend longer times within such cycles before their irreversible conversion to aromatics. ${ }^{9,16}$ At low conversions, propene molecules do not show a binomial ${ }^{13} \mathrm{C}$ isotopomer distribution and contain mostly one ${ }^{13} \mathrm{C}$ atom, because they form initially only via direct dehydrogenation of propane (Figure 4). As the propane conversion increases with increasing contact time, propene approaches a binomial isotopomer distribution, as it increasingly forms also from oligomerization-cracking cycles after significant isotopic scrambling (Figure 4). At higher propane conversions, where propene shows a binomial ${ }^{13} \mathrm{C}$ distribution, propane isotopomers still show predominantly one ${ }^{13} \mathrm{C}$, indicating that propane dehydrogenation steps are essentially irreversible. Ethene molecules also contain one ${ }^{13} \mathrm{C}$ atom at low propane conversions, because they form via cracking of propane with a single ${ }^{13} \mathrm{C}$ at the secondary position. The ${ }^{13} \mathrm{C}$ distribution also approaches a binomial distribution at higher conversions, as ethene increasingly forms via oligomerization-cracking cycles. Ethane and ethene show similar ${ }^{13} \mathrm{C}$ contents and isotopomer distributions, suggesting that ethane forms via ethene hydrogenation.

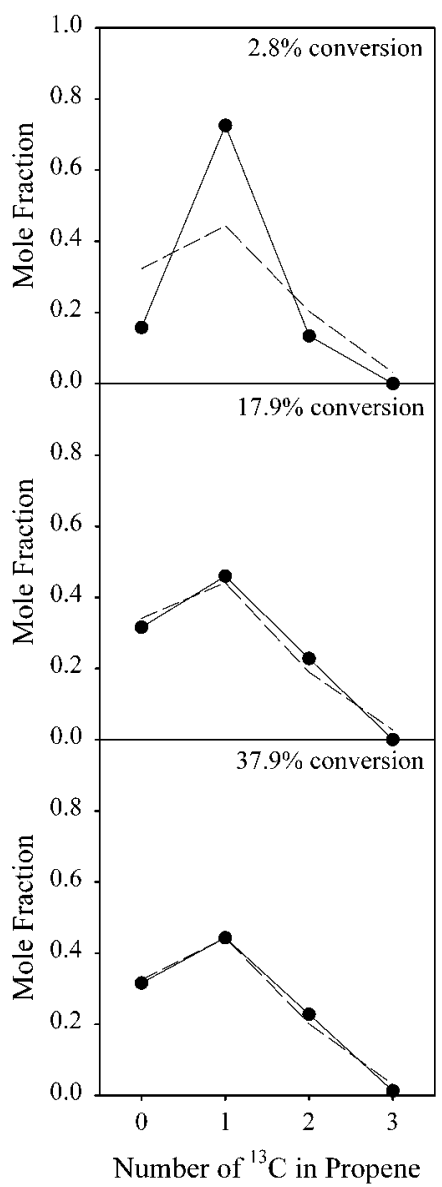

Figure 4. ${ }^{13} \mathrm{C}$ distribution in propene at varying propane conversion: experimental (data points) and binomial distribution (dashed line) $[\mathrm{Co} /$ $\mathrm{Al}=0.22,773 \mathrm{~K}, 14.3 \mathrm{kPa} 2{ }^{13} \mathrm{C}_{-} \mathrm{C}_{3} \mathrm{H}_{8}$, balance $\left.\mathrm{He}\right]$.

The ${ }^{13} \mathrm{C}$ isotopomer distribution in benzene is shown in Figure 5 ; it resembles those measured for toluene and xylene isomers. At very low conversions, benzene has a slightly sharper than binomial distribution on $\mathrm{Co} / \mathrm{H}-\mathrm{ZSM} 5$, as also found on $\mathrm{Zn} /$ $\mathrm{H}-\mathrm{ZSM} 5^{9,16}$ because cations increase the rate of removal of alkenes from oligomerization-cracking cycles, causing the residence times to become too short for complete isotopic scrambling of alkenes before irreversible conversion to aromatics. At higher conversions, benzene shows a binomial ${ }^{13} \mathrm{C}$ isotopomer distribution, similar to that found for H-ZSM5, because aromatics form only after significant residence times of alkenes within oligomerization-cracking cycles (Figure 5).

The approach of isotopomer distributions to binomial for each product increases with increasing conversion (Figure 6). We define the approach to binomial as the isotopic conversion shown in eq 2.17 This isotopic conversion is defined as zero when the product is that expected from the pure $2-{ }^{13} \mathrm{C}$-propane reactant and $100 \%$ when the product shows a binomial distribution:

$$
X=\left[1-\frac{\sum_{i}\left(a_{i}-a_{i}^{b}\right)^{2}}{\sum_{i}\left(a_{i}^{0}-a_{i}^{b}\right)^{2}}\right] \times 100
$$

Here, $a_{i}{ }^{0}, a_{i}$, and $a_{i}^{b}(i=0,1, \ldots n ; n=$ total number of carbons) represent the mole fractions of isotopomers with $i{ }^{13} \mathrm{C}$-atoms expected from unscrambled reactant $\left(a_{i}{ }^{0}\right)$, measured during reaction $\left(a_{i}\right)$, and calculated for a binomial distribution $\left(a_{i}^{b}\right)$. 


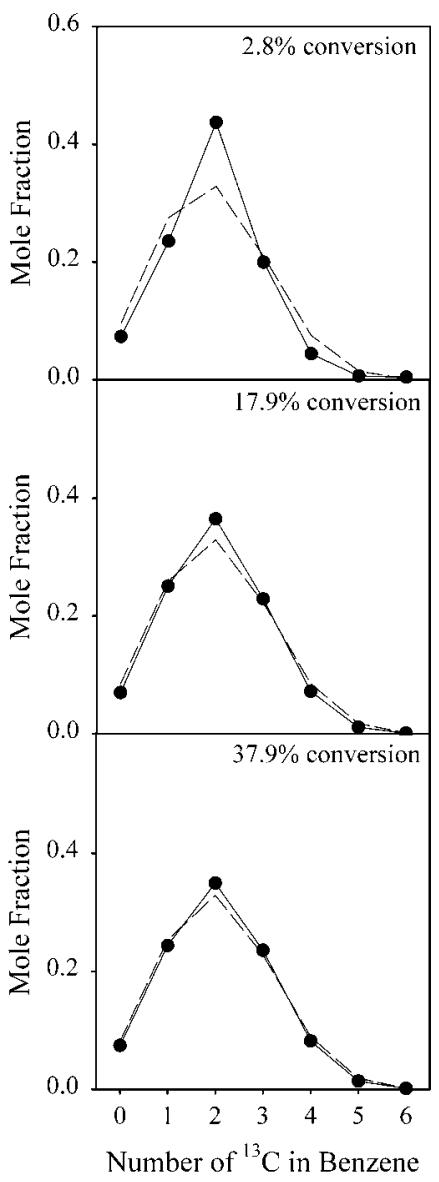

Figure 5. ${ }^{13} \mathrm{C}$ distribution in benzene at varying propane conversion: experimental (data points) and binomial distribution (dashed line) $[\mathrm{Co} /$ $\mathrm{Al}=0.22,773 \mathrm{~K}, 14.3 \mathrm{kPa} 2{ }^{13} \mathrm{C}_{-} \mathrm{C}_{3} \mathrm{H}_{8}$, balance $\left.\mathrm{He}\right]$.

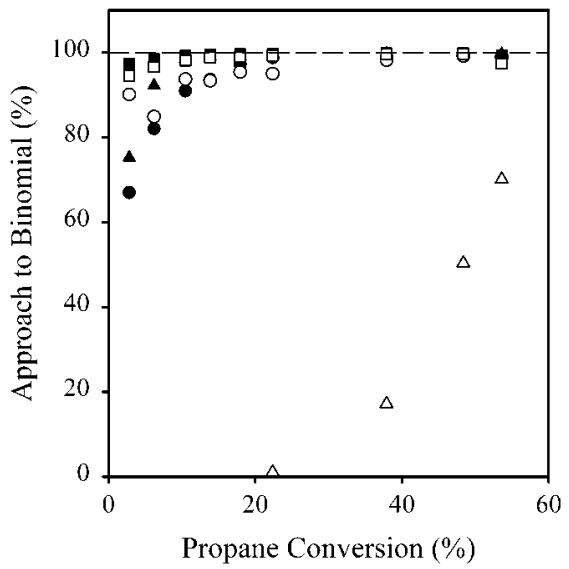

Figure 6. Approach to binomial distribution of products and propane reactant: ethene (solid circles), ethane (open circles), propene (solid triangles), propane (open triangles), benzene (solid squares), toluene (open squares) $\left[\mathrm{Co} / \mathrm{Al}=0.22,773 \mathrm{~K}, 14.3 \mathrm{kPa} 2-{ }^{13} \mathrm{C}-\mathrm{C}_{3} \mathrm{H}_{8}\right.$, balance $\mathrm{He}]$.

This isotopic conversion is a measure of the residence time of alkenes within oligomerization-cracking cycles. Longer residence times within these cycles enable the alkenes to become isotopically scrambled, leading to a higher isotopic conversion. ${ }^{17}$

Ethene and propene show lower isotopic conversions than aromatics because ethene and propene are initially formed via propane cracking and dehydrogenation, respectively, while aromatics form only from alkenes that exit oligomerizationcracking cycles (Figure 6). Since ethane forms via ethene hydrogenation, it shows a similar approach to binomial as

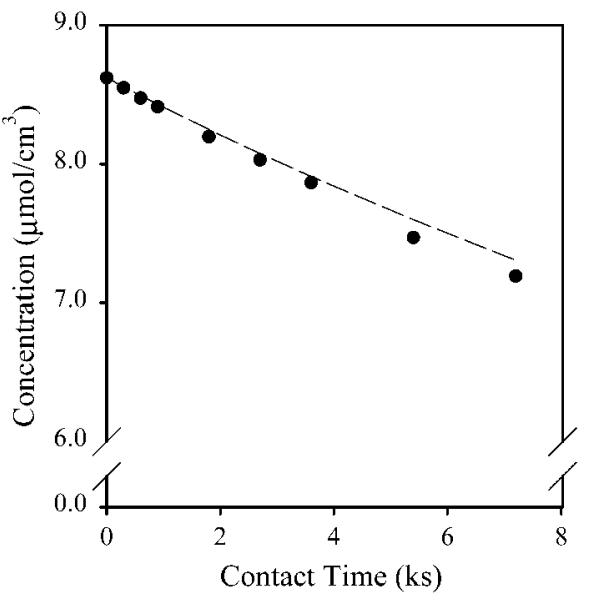

Figure 7. Comparison of experimental concentration (data points) of propane reactant to calculated or predicted concentration from model (dashed lines) $\left[\mathrm{Co} / \mathrm{Al}=0.05,773 \mathrm{~K}, 21.3 \mathrm{kPa} \mathrm{C}_{3} \mathrm{H}_{8}, 60 \mathrm{kPa} \mathrm{H}_{2}\right.$, balance $\mathrm{He}]$.

ethene. All of the products show a binomial distribution at high conversions, because they are formed after significant residence times within oligomerization-cracking cycles. The propane isotopomer distribution becomes increasingly binomial as conversion increases. This reflects the formation of some propane from propene molecules formed in oligomerizationcracking cycles. Propane molecules do not reach a binomial distribution, even at the highest conversion levels, because propane dehydrogenation steps are far from equilibrium.

The selectivity, product site-yield, and isotopic data presented are consistent with the propane conversion pathways shown in Scheme 1, which were also proposed on H-ZSM5 from kinetic and isotopic tracer studies. ${ }^{16}$ Propane undergoes initial dehydrogenation to form propene and $\mathrm{H}_{2}$ or cracking to form methane and ethene. Propene and ethene can enter oligomerizationcracking cycles where $\mathrm{C}-\mathrm{C}$ bonds are broken and re-formed several times before a stable aromatic molecule forms via cyclization and dehydrogenation steps. Products exit this cycle either via dehydrogenation steps to form aromatics and $\mathrm{H}_{2}$ or via hydrogenation or cracking steps to form alkanes. Some of the hydrogen atoms formed in primary propane dehydrogenation and secondary dehydrocyclization reactions are removed by recombinative desorption as $\mathrm{H}_{2}$, while the rest are used in alkene hydrogenation and cracking reactions to form ethane, propane, and larger alkanes.

Effects of $\mathrm{H}_{2}$ and $\mathrm{Co}^{2+}$ Cations on Individual Reaction Steps. The rate constants for the individual steps in Scheme 1 were obtained on $\mathrm{H}-\mathrm{ZSM} 5$ and on $\mathrm{Co} / \mathrm{H}-\mathrm{ZSM} 5$ with varying $\mathrm{Co} / \mathrm{Al}$ ratio at various concentrations of $\mathrm{H}_{2}$ in the reactant mixture. First, the kinetic model was used to describe the results on $\mathrm{Co} / \mathrm{H}-\mathrm{ZSM} 5(\mathrm{Co} / \mathrm{Al}=0.05)$ when $\mathrm{H}_{2}$ was added to the gas phase in order to determine the extent to which $\mathrm{H}_{2}$ influences the rate of any of the reaction steps. $\mathrm{H}_{2}$ partial pressures (30$90 \mathrm{kPa})$ well above those formed during propane reaction $(1-3$ $\mathrm{kPa}$ ) were added to the propane reactants; as a result, the amount of $\mathrm{H}_{2}$ present remained constant throughout the range of contact time and propane conversion in these experiments.

Figure 7 shows experimental and predicted propane concentrations using this model. Similar data for methane, ethene, ethane, propene, and aromatics are shown in Figures 8 and 9 for $\mathrm{Co} / \mathrm{H}-\mathrm{ZSM} 5(\mathrm{Co} / \mathrm{Al}=0.05)$ at $60 \mathrm{kPa} \mathrm{H}_{2}$. The kinetic model accurately describes the experimental evolution of all reaction products. Similar agreement with experiment was obtained when 30 or $90 \mathrm{kPa}$ of $\mathrm{H}_{2}$ were added. The dependences of the 


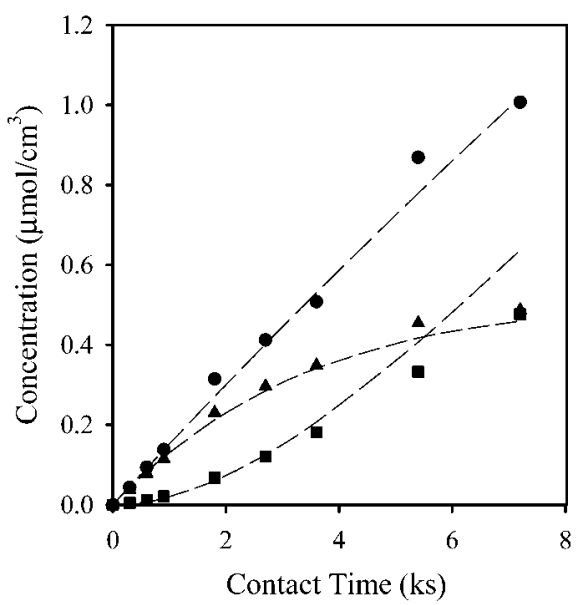

Figure 8. Comparison of experimental concentrations (data points) of products to calculated or predicted concentrations from model (dashed lines): methane (circles), ethene (triangles), and ethane (squares) $\left[\mathrm{Co} / \mathrm{Al}=0.05,773 \mathrm{~K}, 21.3 \mathrm{kPa} \mathrm{C}_{3} \mathrm{H}_{8}, 60 \mathrm{kPa} \mathrm{H}\right.$, balance $\mathrm{He}$.

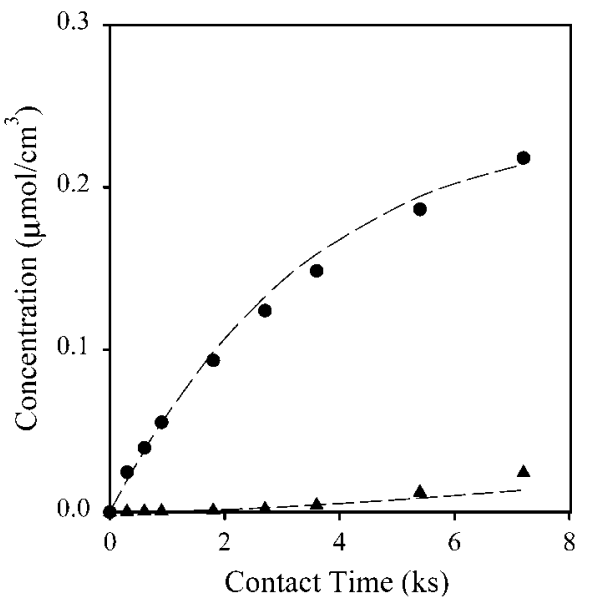

Figure 9. Comparison of experimental concentrations (data points) of products to calculated or predicted concentrations from model (dashed lines): propene (circles) and aromatics (triangles) $[\mathrm{Co} / \mathrm{Al}=$ $0.05,773 \mathrm{~K}, 21.3 \mathrm{kPa} \mathrm{C}_{3} \mathrm{H}_{8}, 60 \mathrm{kPa} \mathrm{H}_{2}$, balance He].

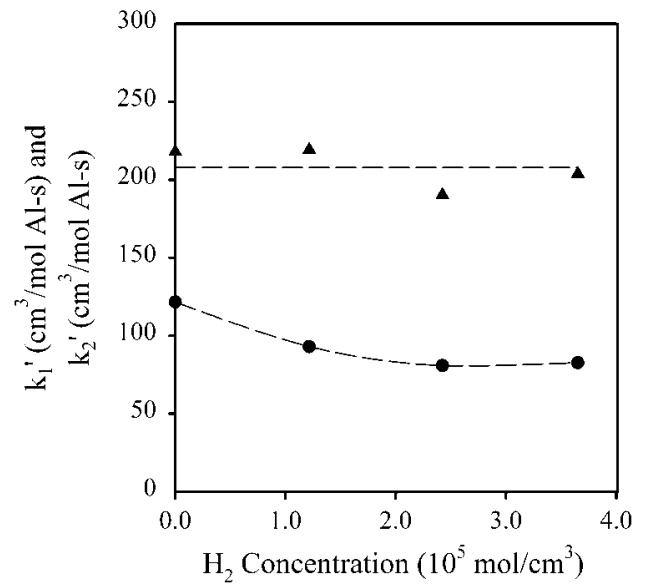

Figure 10. Propane dehydrogenation rate constant $\left(k_{1}{ }^{\prime}\right)$ (circles) and propane cracking rate constant $\left(k_{2}^{\prime}\right)$ (triangles) as a function of $\mathrm{H}_{2}$ concentration present $\left[\mathrm{Co} / \mathrm{Al}=0.05,773 \mathrm{~K}, 20 \mathrm{kPa} \mathrm{C} \mathrm{H}_{8}, 30-90 \mathrm{kPa}\right.$ $\mathrm{H}_{2}$, balance $\left.\mathrm{He}\right]$.

individual rate constants on $\mathrm{H}_{2}$ concentration for Co/H-ZSM5 $(\mathrm{Co} / \mathrm{Al}=0.05)$ are shown in Figures 10 and 11 . These figures show the pseudo first-order rate constants as a function of $\mathrm{H}_{2}$ concentration.

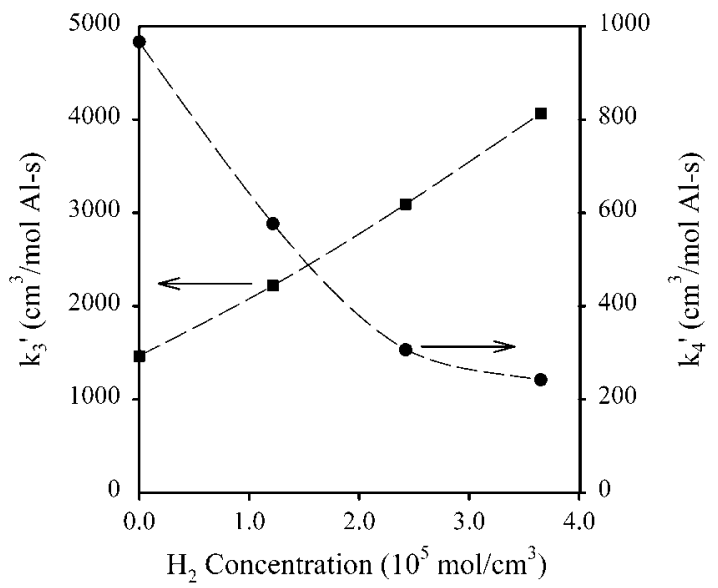

Figure 11. Ethene hydrogenation rate constant $\left(k_{3}{ }^{\prime}\right)$ (squares) and rate constant corresponding to alkene reactions to form aromatics $\left(k_{4}{ }^{\prime}\right)$ (circles) as a function of $\mathrm{H}_{2}$ concentration present $[\mathrm{Co} / \mathrm{Al}=0.05,773$ $\mathrm{K}, 20 \mathrm{kPa} \mathrm{C} \mathrm{H}_{8}, 30-90 \mathrm{kPa} \mathrm{H}_{2}$, balance He].

The primary propane dehydrogenation rate constant $\left(k_{1}{ }^{\prime}\right)$ decreased slightly with increasing $\mathrm{H}_{2}$ concentration (Figure 10). $\mathrm{H}_{2}$ is expected to decrease the concentration of hydrogendeficient intermediates involved in dehydrogenation reactions. Propane cracking rate constants $\left(k_{2}{ }^{\prime}\right)$ are not influenced by $\mathrm{H}_{2}$ (Figure 10). Neither the stoichiometry nor the mechanism of these cracking reactions involves hydrogen and cracking rates are independent of $\mathrm{H}_{2}$. Ethene hydrogenation rate constants $\left(k_{3}{ }^{\prime}\right)$ increase with increasing $\mathrm{H}_{2}$ concentration (Figure 11). As for the propane dehydrogenation step $\left(k_{1}{ }^{\prime}\right)$, the rate constant for alkene conversion to aromatics $\left(k_{4}{ }^{\prime}\right)$ decreases with increasing $\mathrm{H}_{2}$ concentration, because of the lower concentrations of hydrogen-deficient intermediates (Figure 11). The dependence of this rate constant $\left(k_{4}{ }^{\prime}\right)$ on $\mathrm{H}_{2}$ (Figure 11) is stronger than for propane dehydrogenation steps $\left(k_{1}{ }^{\prime}\right)$ (Figure 10), apparently because of the higher hydrogen deficiency of the intermediates required for the aromatization of alkenes, which would make $k_{4}{ }^{\prime}$ more sensitive to $\mathrm{H}_{2}$ than $k_{1}{ }^{\prime}{ }^{1}$

These data show that $\mathrm{H}_{2}(30-90 \mathrm{kPa})$ influences individual reaction rates during propane conversion on $\mathrm{Co} / \mathrm{H}-\mathrm{ZSM} 5$, but the low $\mathrm{H}_{2}$ pressures prevalent $(1-3 \mathrm{kPa})$ during reactions of pure propane would lead to very small changes in rates as $\mathrm{H}_{2}$ accumulates with increasing conversion and contact time. Therefore, a $\mathrm{H}_{2}$ mole balance was included and pseudo-firstorder rate constants were assumed to be independent of $\mathrm{H}_{2}$ pressure over its limited experimental range. This approach was used to describe rates and selectivities during conversion of pure propane reactants on $\mathrm{H}-\mathrm{ZSM} 5$ and on $\mathrm{Co} / \mathrm{H}-\mathrm{ZSM} 5(\mathrm{Co} / \mathrm{Al}=$ $0.05-0.22)$ and to estimate rate constants for all the reactions in Scheme 1.

The effects of Co cations on reaction rates and product selectivities were described previously. ${ }^{1} \mathrm{Co}^{2+}$ cations catalyze the recombinative desorption of hydrogen as $\mathrm{H}_{2}$, by providing alternate pathways for the kinetically relevant $\mathrm{H}_{2}$ removal steps. As a result, $\mathrm{Co}^{2+}$ cations increase propane turnover rates and the rate of formation of dehydrogenated products. ${ }^{1}$ This role of Co cations is similar to those ascribed to $\mathrm{Zn}$ and $\mathrm{Ga}$ in these reactions. ${ }^{2,7,16}$ Here, we report the specific role of Co cations and of acid sites on individual reaction steps - primary dehydrogenation and cracking of propane, secondary hydrogenation of ethene to ethane, and alkene reactions to form aromatics.

Primary propane dehydrogenation rate constants $\left(k_{1}\right)$ increased with increasing Co content, indicating that $\mathrm{Co}^{2+}$ cations increase the rate of the initial dehydrogenation step (Figure 12). This suggests that Co sites catalyze kinetically relevant steps in the 


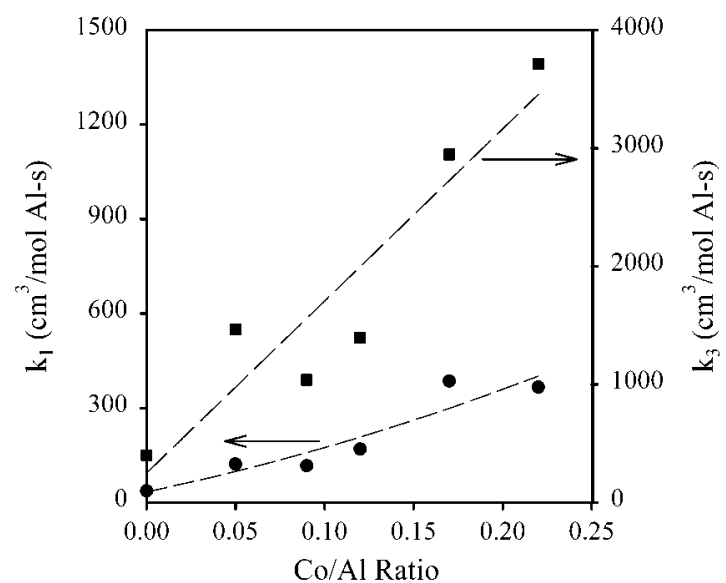

Figure 12. Propane dehydrogenation rate constant $\left(k_{1}\right)$ (circles) and ethene hydrogenation rate constant $\left(k_{3}\right)$ (squares) as a function of $\mathrm{Co} /$ $\mathrm{Al}$ ratio $\left[773 \mathrm{~K}, 20 \mathrm{kPa} \mathrm{C}_{3} \mathrm{H}_{8}\right.$, balance $\left.\mathrm{He}\right]$.

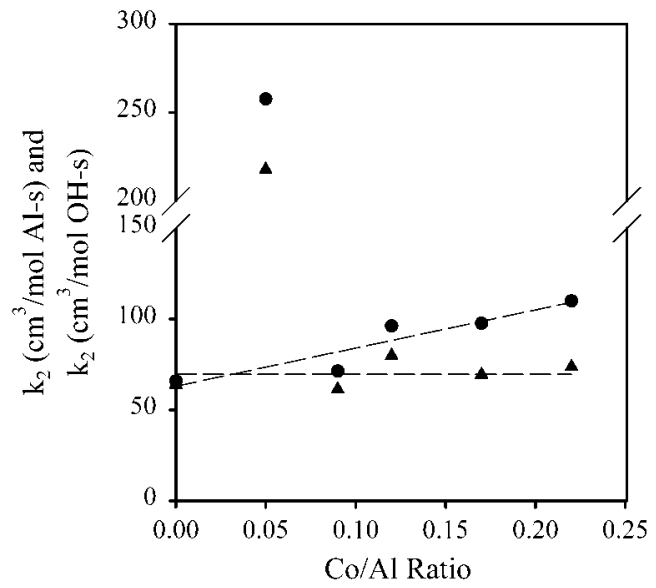

Figure 13. Propane cracking rate constant $\left(k_{2}\right)$ per $\mathrm{Al}$ (triangles) and per $\mathrm{OH}$ (circles) as a function of $\mathrm{Co} / \mathrm{Al}$ ratio $\left[773 \mathrm{~K}, 20 \mathrm{kPa} \mathrm{C}_{3} \mathrm{H}_{8}\right.$, balance $\mathrm{He}]$.

dehydrogenation of propane to propene. A similar role of $\mathrm{Zn}$ and $\mathrm{Ga}$ was reported previously. ${ }^{2,7,16}$

Cracking rate constants $\left(k_{2}\right)$ per $\mathrm{Al}$ are similar for H-ZSM5 and for $\mathrm{Co} / \mathrm{H}-\mathrm{ZSM} 5$ with varying $\mathrm{Co} / \mathrm{Al}$ ratio, except for the $\mathrm{Co} / \mathrm{H}-\mathrm{ZSM} 5$ with a $\mathrm{Co} / \mathrm{Al}$ ratio of 0.05 (Figure 13). The reason for its large rate constant is unclear. Co does not seem to affect the cracking of propane to methane and ethene. This indicates that the propane cracking reactions occur on acid sites. The cracking rate constants $\left(k_{2}\right)$ per $\mathrm{OH}$ remaining after exchange are shown in Figure 13 and increase very slightly with increasing $\mathrm{Co} / \mathrm{Al}$ ratio. This suggests that cracking does not occur on Co cations and that any effect of such cations on the acid chemistry of zeolitic $\mathrm{OH}$ groups is very small. Ethene hydrogenation rate constants $\left(k_{3}\right)$ (Figure 12) increase with increasing $\mathrm{Co} / \mathrm{Al}$ ratio, because Co cations increase both the desorption of hydrogen during propane dehydrogenation, but also its microscopic reverse, the dissociative adsorption of $\mathrm{H}_{2}$, which provides the hydrogen required for ethene hydrogenation.

Rate constants for alkene conversion to aromatics $\left(k_{4}\right)$ are shown in Figure 14 as a function of the $\mathrm{Co} / \mathrm{Al}$ ratio. This rate constant increases with increasing Co content. This suggests that Co cations enhance alkene dehydrogenation and cyclization reactions to form aromatics. The reaction step leading to aromatics from alkenes is strongly influenced by the hydrogen removal ability of cations. ${ }^{1}$ Therefore, increasing amounts of Co provide greater hydrogen removal rates and cause $k_{4}$ to increase with Co content. Unreliable experimental measurements

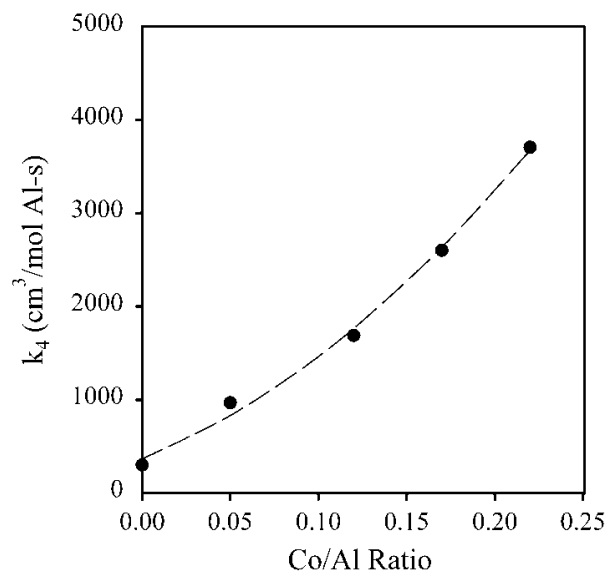

Figure 14. Rate constant corresponding to alkene reactions to form aromatics $\left(k_{4}\right)$ as a function of $\mathrm{Co} / \mathrm{Al}$ ratio $\left[773 \mathrm{~K}, 20 \mathrm{kPa} \mathrm{C}_{3} \mathrm{H}_{8}\right.$, balance $\mathrm{He}]$.

of the aromatics selectivity on one of the $\mathrm{Co} / \mathrm{H}-\mathrm{ZSM} 5$ samples $(\mathrm{Co} / \mathrm{Al}=0.09)$ prevented us from obtaining an accurate value for $k_{4}$.

In summary, the kinetic model proposed in Scheme 1 leads to rate constants that accurately describe experimental results. The influence of $\mathrm{H}_{2}$ on the different reaction steps and the dependence of the different rate constants on the amount of exchanged Co cations in H-ZSM5 are consistent with the previously proposed role of these cations in providing sites for kinetically relevant hydrogen removal steps during propane dehydrogenation reactions.

Reversibility of Hydrogen Recombinative Desorption Steps and Role of Co Cations. The reversibility of $\mathrm{H}_{2}$ recombinative desorption steps during propane conversion on $\mathrm{Co} / \mathrm{H}-\mathrm{ZSM} 5$ and $\mathrm{H}-\mathrm{ZSM} 5$ was probed by measuring the deuterium content in products formed from $\mathrm{C}_{3} \mathrm{H}_{8} / \mathrm{D}_{2}$ reactant mixtures. Quasi-equilibrated adsorption-desorption steps would lead to the predominant presence of D-atoms in reaction products, while irreversible desorption steps would lead exclusively to $\mathrm{H}$-atoms from propane in the products. Similar experiments have been previously reported on H-ZSM5, Zn/ H-ZSM5, and Ga/H-ZSM5, 7,9,18 for which the deuterium content in products was markedly increased by the presence of exchanged cations.

On $\mathrm{Co} / \mathrm{H}-\mathrm{ZSM} 5$, the deuterium fraction in all reaction products is similar for each given catalyst and the deuterium isotopomer distribution is binomial for all products at all contact times. This indicates that products sample statistically from a common pool of $\mathrm{H}$ and $\mathrm{D}$ atoms present in the prevalent pool of adsorbed reactive intermediates. Deuterium fractions in propene, benzene, and toluene as a function of propane conversion are shown on H-ZSM5 and on Co/H-ZSM5 samples with $\mathrm{Co} / \mathrm{Al}$ ratios of 0.12 and 0.31 (Figure 15). The deuterium content in the products of $\mathrm{Co} / \mathrm{H}-\mathrm{ZSM} 5$ is higher than $\mathrm{H}-\mathrm{ZSM} 5$ and increases with increasing Co content.

Initially, protium atoms at acidic $\mathrm{OH}$ groups are incorporated into the reaction products. ${ }^{19}$ As the protons are exchanged with deuterium, the $\mathrm{D}$ fraction in the products increases during initial contact between a $\mathrm{D}_{2}$-containing gas phase and a protiumcontaining surface (Figure 15). At higher contact time (and propane conversion), the deuterium content decreases because of the formation of gas-phase $\mathrm{H}_{2}$ during propane conversion, which dilutes the isotopically pure $\mathrm{D}_{2}$ initially present in the gas phase (Figure 15). The linear portion of the curve is extrapolated to zero propane conversion (and contact time) in 


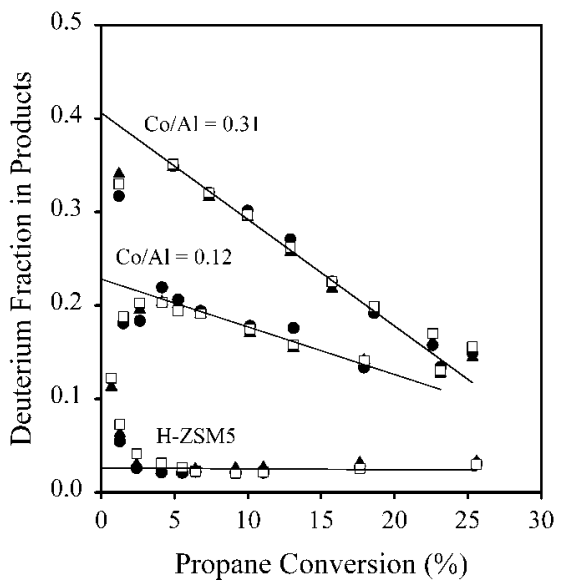

Figure 15. Deuterium fraction in propene (solid circles), benzene (solid triangles), and toluene (open squares) $[\mathrm{H}-\mathrm{ZSM} 5, \mathrm{Co} / \mathrm{Al}=0.12$ and $0.31,773 \mathrm{~K}, 21.4 \mathrm{kPa} \mathrm{C}_{3} \mathrm{H}_{8}, 11.0 \mathrm{kPa} \mathrm{D}$, balance $\left.\mathrm{He}\right]$.

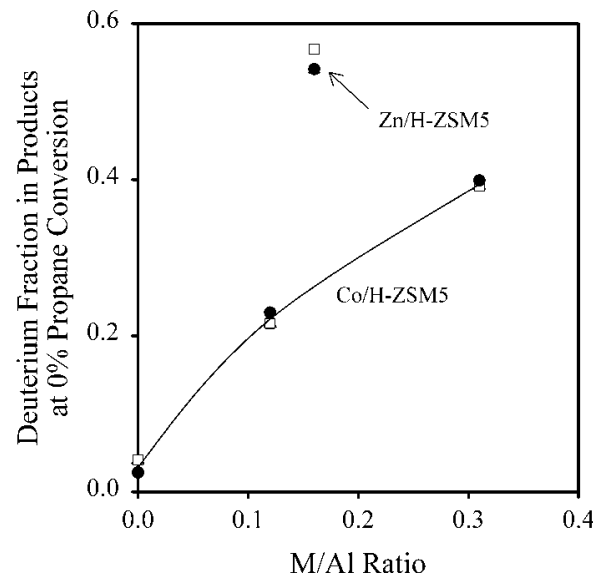

Figure 16. Deuterium fraction in propene (solid circles), benzene (solid triangles), and toluene (open squares) at $0 \%$ propane conversion with varying M/Al Ratio [773 K, $21.4 \mathrm{kPa} \mathrm{C}_{3} \mathrm{H}_{8}, 11.0 \mathrm{kPa} \mathrm{D}$, balance $\mathrm{He}$.

order to correct for the isotopic dilution of $\mathrm{D}_{2}$ in the gas phase with $\mathrm{HD}$ and $\mathrm{H}_{2}$ as propane conversion increases (Figure 15).

These deuterium fractions in several reaction products (extrapolated to zero contact time) are shown as a function of $\mathrm{Co} / \mathrm{Al}$ ratio in Figure 16. $\mathrm{Co}^{2+}$ cations catalyze $\mathrm{H}_{2}$ adsorptiondesorption steps and thus their reversibility during propane reactions. As a result, $\mathrm{D}$-atoms from $\mathrm{D}_{2}$ communicate more effectively with the pool of adsorbed organic species present during steady-state propane conversion reactions. Zn/H-ZSM5 $(\mathrm{Zn} / \mathrm{Al}=0.16)$ shows a higher $\mathrm{D}$ content in these products than either $\mathrm{Co} / \mathrm{H}-\mathrm{ZSM} 5$ sample $(\mathrm{Co} / \mathrm{Al}=0.12$ and 0.31$)$, suggesting that $\mathrm{Zn}^{2+}$ cations catalyze hydrogen adsorption-desorption steps more effectively than $\mathrm{Co}^{2+}$ cations. ${ }^{1,10}$

\section{Conclusions}

Contact time effects on product selectivity and product siteyields and the ${ }^{13} \mathrm{C}$ content and isotopomer distribution in products formed from $2-{ }^{13} \mathrm{C}$-propane show that propane conversion pathways on $\mathrm{Co} / \mathrm{H}-\mathrm{ZSM} 5$ resemble those reported previously on H-ZSM5. ${ }^{16}$ Equimolar amounts of propene and $\mathrm{H}_{2}$, formed via propane dehydrogenation, and of ethene and methane, formed via cracking reactions, are primary products. Secondary products include ethane, formed by ethene hydrogenation, and aromatics, formed by dehydrocyclization reactions of $\mathrm{C}_{6}+$ alkenes participating in rapid oligomerization-cracking cycles of alkenes. Co cations catalyzed the removal of hydrogen as $\mathrm{H}_{2}$ from a pool of reactive intermediates involved in dehydrogenation and dehydrocyclization steps, as also found for $\mathrm{Ga}$ and $\mathrm{Zn}$ cations. ${ }^{1,2,7-9} \mathrm{Co}$ cations increase the rate constants for propane dehydrogenation $\left(k_{1}\right)$, ethene hydrogenation $\left(k_{2}\right)$, and alkene dehydrocyclization $\left(k_{4}\right)$ because Co cations catalyze the kinetically relevant hydrogen adsorption-desorption steps for these reactions. Propane cracking rate constants are not influenced by $\mathrm{H}_{2}$ or by Co cations, because these reactions occur on Bronsted acid sites. Co cations increase the reversibility of hydrogen removal steps and the communication between the surface and the gas-phase hydrogen pools.

Acknowledgment. This work was supported by the National Science Foundation (CTS-96-13632) under the technical supervision of Dr. Raul Miranda as part of the NSF-EPA joint partnership. The authors acknowledge Professor Guido BuzziFerraris at the Politecnico di Milano in Italy for the use of his regression analysis library, Burelib.for, and Dario Pinna for bringing the library to our attention and assisting in its implementation and use.

\section{References and Notes}

(1) Li, W.; Yu, S. Y.; Meitzner, G. D.; Iglesia, E. J. Phys. Chem. B 2001, 105, 1176.

(2) Mole, T.; Anderson, J. R.; Creer, G. Appl. Catal. 1985, 17, 141.

(3) Kitagawa, H.; Sendodo, Y.; Ono, Y. J. Catal. 1986, 101, 12.

(4) Gnep, N. S.; Doyemet, J. Y.; Guisnet, M. J. Mol. Catal. 1988, 45, 281.

(5) Iglesia, E.; Baumgartner, J. E.; Price, G. L. J. Catal. 1992, 134,

(6) Ono, Y. Catal. Rev.-Sci. Eng. 1992, 34, 179.

(7) Biscardi, J. A.; Iglesia, E. Catal. Today 1996, 31, 207. 192.

(8) Biscardi, J. A.; Meitzner, G. D.; Iglesia, E. J. Catal. 1998, 179,

(9) Biscardi, J. A.; Iglesia, E. J. Catal. 1999, 182, 117.

(10) Li, W.; Biscardi, J. A.; Yu, S. Y.; Iglesia, E., unpublished results.

(11) Yu, S. Y.; Li, W.; Iglesia, E. J. Catal. 1999, 187, 257.

(12) Borry, R. W.; Kim, Y. H.; Huffsmith, A.; Reimer, J. A.; Iglesia, E. J. Phys. Chem. B 1999, 103, 5787.

(13) Price, G. L. Ind. Eng. Chem. Res. 1989, 28, 839.

(14) Kahaner, D.; Moler, C.; Nash, S. Numerical Methods and Software; Prentice Hall: New York, 1988.

(15) Buzzi-Ferraris, G. 2001. Burelib.for, Department of Industrial Chemistry and Chemical Engineering, Politecnico di Milano, Italy.

(16) Biscardi, J. A.; Iglesia, E. J. Phys. Chem. B 1998, 102, 9284.

(17) Li, W.; Yu, S. Y.; Iglesia, E. J. Catal. 2001, 175, 203.

(18) Yu, S. Y.; Biscardi, J. A.; Iglesia, E. J. Phys. Chem., submitted.

(19) Narbeshuber, T. F.; Stockenhuber, M.; Brait, A.; Seshan, K.; Lercher, J. A. J. Catal. 1996, 160, 183. 